\title{
Clinical and endoscopic characteristics of post-colonoscopy colorectal cancers detected within 10 years after a previous negative examination*
}

\section{(ㄷ)(우우}

\author{
Authors \\ Kenta Kodama**, 1,2, Shin-ei Kudo', Hideyuki Miyachi**, 1, Kunihiko Wakamura1, Yasuharu Maeda', Katsuro

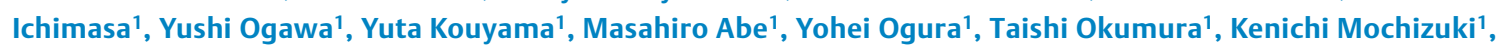 \\ Yosuke Minegishi', Misaki Ishiyama', Yuichi Mori¹, Masashi Misawa', Toyoki Kudo¹, Takemasa Hayashi', Fumio \\ Ishida', Daisuke Watanabe ${ }^{3,4}$
}

Institutions

1 Digestive Disease Center, Showa University Northern Yokohama Hospital, Yokohama, Japan

2 Division of Gastroenterology, Japanese Red Cross Society Fukushima Hospital, Fukushima, Japan

3 Division of Gastroenterology, Department of Internal Medicine, Kobe University Graduate School of Medicine, Kobe, Japan

4 Division of Gastroenterology, Department of Internal Medicine, University of Michigan, Ann Arbor, Michigan, United States

submitted 29.6.2020

accepted after revision 1.2.2021

\section{Bibliography}

Endosc Int Open 2021; 09: E1472-E1479

DOI 10.1055/a-1518-6754

ISSN 2364-3722

(c) 2021. The Author (s).

This is an open access article published by Thieme under the terms of the Creative Commons Attribution-NonDerivative-NonCommercial License, permitting copying and reproduction so long as the original work is given appropriate credit. Contents may not be used for commercial purposes, or adapted, remixed, transformed or built upon. (https://creativecommons.org/licenses/by-nc-nd/4.0/)

Georg Thieme Verlag KG, Rüdigerstraße 14,

70469 Stuttgart, Germany

\section{Corresponding author}

Shin-ei Kudo, MD, PhD, Digestive Disease Center, Showa University Northern Yokohama Hospital, 35-1 Chigasaki Chuo, Tsuzuki-ku, Yokohama City, Kanagawa 224-8503, Japan

Fax: +81-45-949-7535

kudos@med.showa-u.ac.jp

\section{ABSTRACT}

Background and study aims We sometimes encounter colorectal cancer (CRC) that is discovered during the time interval between initial colonoscopy and the recommended follow-up examination. Although several studies reported such cases of CRC, most were based on registry data, which implied that the endoscopic quality was not consistent or guaranteed. We aimed to clarify these clinical and endoscopic characteristics at our high-volume center where a retrospective survey could be precisely performed.

Patients and methods We retrospectively analyzed patients with CRC who underwent endoscopic resection or surgery from April 2002 to December 2010, categorizing them into two groups: a "study group" of patients with a negative colonoscopy during the previous 10 years, and a "control group" of patients without a previous colonoscopy or with a previous colonoscopy more than 10 years prior.

Results A total of 2042 patients had CRC, among which 55 patients were classified into the study group and the remaining 1989 into the control group. The CRC cases in the study group showed a significant association with smaller (<30 mm) tumor size (odds ratio [OR] 2.3; $95 \%$ confidence interval $[\mathrm{Cl}]$ 1.3-4.0) and proximal tumor site (OR 1.7; $95 \%$ Cl 0.9-2.9). In addition, right-sided and depressed-type T1 CRCs were significantly more common in the study group. Conclusions Tumor size and location were associated with CRCs detected within 10 years after the negative examination. In addition, depressed-type T1 CRCs were more common. Therefore, we should pay more attention to small, right-sided, or depressed-type tumors in daily colonoscopy.

\footnotetext{
* Meeting presentations: Part of the present study was presented at the United European Gastroenterology Week 2013, Berlin, Germany, 16th October 2013 (poster presentation).
}

\footnotetext{
** These authors contributed equally.
} 


\section{Introduction}

Colorectal cancer (CRC) is the major cause of death by malignancy in Japan as well as in western countries [1]. On the other hand, adenomas are accepted as precursor lesions for most CRC cases [2]. To date, most deaths from CRC are currently prevented by regular colonoscopy coupled with the removal of adenomas. In fact, adenomas can be decreased by $76 \%$ to $90 \%$, with a significant reduction in CRC mortality, in patients who undergo a clearing colonoscopy $[3,4]$.

In routine clinical practice, a CRC is sometimes discovered during the time interval between initial colonoscopy and the recommended follow-up examination. Such CRCs that are found before the expected interval after the initial colonoscopy are named interval colorectal cancers, or post-colonoscopy CRCs (PCCRCs), while the World Endoscopy Organization (WEO) consensus states that the term "interval cancers" should be used only for screening and surveillance colonoscopy programs [5]. Although associations between PCCRC and several clinical risk factors have been reported [6-8], these results were mainly based on registry-based administrative data such as the Ontario Cancer Registry [8], the Canadian Institute for Health Information-Discharge Abstract Database [9], or Manitoba's provincial physicians' billing claims database [10]. Little information has been reported at a high-volume center where a retrospective survey could be precisely performed.

Although the annual 2-day fecal immunochemistry test (FIT) method is commonly used in population-based CRC screening programs in Japan, total colonoscopy has recently been usedin situations such as CRC screening during medical check-up examinations. A 10-year screening interval is recommended after a negative initial colonoscopy [11], while this strategy may not work efficiently when considering the presence of PCCRC. In addition, we also considered that it would be more informative to elucidate the characteristics of PCCRC that were identified during the 10-year interval. Therefore, the aim of this study was to evaluate the characteristics of PCCRC that were observed during the 10-year interval based on large cohort data obtained at our flagship gastrointestinal center in order to provide endoscopists with useful information for daily practice.

\section{Patients and methods}

\section{Patients and clinical data}

We retrospectively analyzed patients with CRC who underwent endoscopic resection or surgery at our hospital from April 2002 to December 2010. Hereditary CRC and appendiceal cancer were excluded from the final analysis. Written informed consent was obtained from all patients before initial colonoscopy or surgery. Patients whose previous colonoscopy was not completed were excluded. When identification of the appendiceal orifice or intubation of the terminal ileum was endoscopically recorded, the colonoscopy was considered to be completed. In this study, we regarded PCCRC as "interval type PCCRC," which was identified before the next recommended screening or surveillance examination, referring to the WEO Consensus Statements on Post-Colonoscopy and Post-Imaging Colorectal Can- cer [5]. For the analysis, all eligible patients with CRC were divided into two groups as follows: a "study group" was defined as patients with CRC with a negative colonoscopy during the previous 1 to 10 years, and a "control group" was defined as all patients except for those in the study group, that is patients with CRC without a previous colonoscopy, or with a previous colonoscopy less than one year previously and more than 10 years prior. Therefore, preoperative examination would not be included in the study group. In this study, a negative colonoscopy indicated that the examination results revealed no or only a few benign polyps (hyperplastic polyps of $10 \mathrm{~mm}$ or less in size in the rectum or sigmoid colon) that were diagnosed by magnifying observation.

Information on age, sex, and tumor size, location, and stage [12] was reviewed in the electronic record system. In cases of T1 CRC, morphology of the lesions was also reviewed. The morphology was classified as depressed-, flat- or protruded-type according to Kudo's morphological development classification [13-15]. Accordingly, in this study, mixed-type T1 cancers such as "Ila+IIc" or "Is+IIC" were classified as "depressedtype".

\section{Preparation and colonoscopy}

Before the examination, patients underwent bowel preparation with 2 to $3 \mathrm{~L}$ of polyethylene glycol solution. Diazepam or midazolam and butyl-scopolamine or glucagon were used intravenously for sedation and prevention of peristalsis, respectively. Colonoscopy was performed using a magnifying colonoscope (CF-240ZI, CF-H260AZI, PCF-240ZI; Olympus Corp., Tokyo, Japan). All detected neoplasms were diagnosed based on the pit pattern classification system described by Kudo et al. [16]. Each diagnosis was recorded into the database just after colonoscopy. Lesion size, location, and morphology were also measured and recorded.

\section{Pathological evaluation}

The specimens were examined by one pathologist based on the World Health Organization criteria and the Japanese Society for Cancer of the Colon and Rectum guidelines, as previously described [12]. Briefly, all resected lesions were retrieved and immediately fixed in a $10 \%$ buffered formalin solution for 24 to 48 hours. Among them, T1 CRC lesions were carefully observed with a focus on the pit pattern using a stereomicroscope. Subsequently, they were cut at the point where the deepest invasion area could be exposed on the cut end surface. The other histological specimens were cut into parallel 2- to 3-mm-thick sections. Tumor size was measured after formalin fixation.

\section{Statistical analysis}

We analyzed clinicopathological factors using a Fisher exact test and Welch's t-test. A $P<0.05$ was considered significant. Multivariate logistic regression analysis was performed to calculate odds ratios (ORs) and $95 \%$ confidence intervals (Cls) after accounting for potential confounders. All data were presented as the mean \pm standard deviation. We conducted all ana- 
lyses using JMP software version 10.0.2 (SAS Institute, Cary, North Carolina, United States).

\section{Ethical considerations}

This study was approved by the institutional review board of Showa University Northern Yokohama Hospital (approval number: 19H068).

\section{Results}

A total of 46,891 colonoscopies were performed during the study period (April 2002 to December 2010). Among them, 2050 CRC (excluding hereditary CRC) patients were identified, and then eight appendix cancer cases were excluded. Of these 2042 subjects, 53 patients who underwent another colonoscopy within 10 years after the previous negative colonoscopy were classified as the study group, while the remaining 1989 patients were assigned to the control group ( $\vee$ Fig. 1 ). The indications of colonoscopy in the study group are shown in - Table 1. The interval of colonoscopies in the study group was $756.7 \pm 642.1$ days. Typical cases in the study group are shown in $>$ Fig. 2 and $>$ Fig. 3.

\section{Demographic and tumor characteristics among the study and control groups}

Matching the 55 patients of the study group with the $1989 \mathrm{pa}-$ tients of the control group, in the study group mean age and tumor size were $68.9 \pm 11.3$ years and $26.3 \pm 20.2 \mathrm{~mm}$, respectively, and in the control group mean age and tumor size were $65.6 \pm 11.8$ years and $40.7 \pm 24.1 \mathrm{~mm}$, respectively ( $\downarrow$ Table 2 and $\bullet$ Supplementary Table 1 ). There were more males than females in both groups (study group: $66.0 \%$ vs. $34.0 \%$; control group: $56.6 \%$ vs. $43.4 \% ; P=0.22$ ). In the study group, although the rectum was the most common location $(n=14,26.4 \%), 12$ colorectal neoplasms (22.6\%) were also located in the ascending colon. Regarding tumor stage, T1 stage was most common in the study group ( $n=22,41.5 \%)$, while T3 stage occurred most frequently in the control group $(n=907,45.6 \%)$. Additionally, when the study period was divided into two terms (12-36 and 36-120 months) within the study group, tumor size was significantly smaller in the 12 - to 36 -month subgroup $(23.8 \pm 15.7 \mathrm{~mm})$ than in the 36 - to 120 -month subgroup (45.7 $\pm 38.1 \mathrm{~mm}$ ), and no significant differences were observed in age (years old), sex (male/female), tumor location (C,A,T/D,S,R), or tumor stage (T1/Others).

\section{Risk factors for CRC in patients with a prior negative colonoscopy}

To determine demographic and tumor factors associated with CRC in patients with a prior negative colonoscopy, we performed a multivariate logistic analysis of the study group compared with the control group ( $\vee$ Table 3 ). Age, sex, and tumor stage were not significantly associated with CRC in the study group. In contrast, the study group showed a strong association with smaller ( $<30 \mathrm{~mm}$ ) tumor size (OR $2.8 ; 95 \% \mathrm{Cl} 1.4-5.3)$. In addition, the proximal tumor site was also independently associated with CRC in the study group (OR $2.0 ; 95 \% \mathrm{Cl} 1.2-3.5$ ).
Apr. 2002

Dec. 2010

$<2042$ patients were detected $>$

Previous $1-10$ years 1 year

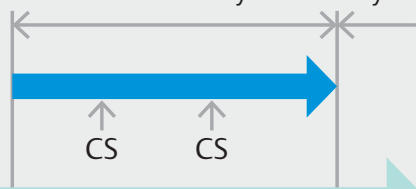

No colonoscopy examination
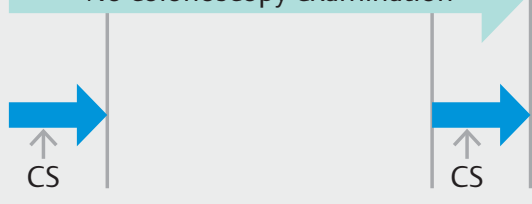

Control group

(1989 cases)

- Fig. 1 Study algorithm. A total of 46891 colonoscopies were performed between April 2002 and December 2010. Among them, 2050 patients with CRC were identified, and eight cases of appendiceal cancer were excluded. Among these 2042 subjects, 53 patients who underwent another colonoscopy within 10 years after the previous negative colonoscopy were classified as the study group, while the remaining 1989 patients were assigned to the control group.

- Table 1 Indications for colonoscopy in the study group $(n=53)$.

\begin{tabular}{|l|l|}
\hline Indication for colonoscopy (current history) & $\mathbf{n}(\%)$ \\
\hline Positive fecal occult blood test & $16(30.2 \%)$ \\
\hline Surveillance after endoscopic treatment for polyps & $9(17.0 \%)$ \\
\hline Surveillance after surgery for colorectal cancers & $8(15.1 \%)$ \\
\hline Hematochezia & $7(13.2 \%)$ \\
\hline Anemia & $4(7.5 \%)$ \\
\hline Medical checkup (no symptoms) & $4(7.5 \%)$ \\
\hline Abdominal bloating & $2(3.8 \%)$ \\
\hline Constipation & $2(3.8 \%)$ \\
\hline Abdominal pain & $1(1.9 \%)$ \\
\hline
\end{tabular}

\section{Morphological and distributional features of T1 tumors in patients with a prior negative colonoscopy}

Finally, we compared the characteristics of the location and morphology of T1 CRC between the Study and control group. As shown in > Table 4, T1 CRC in the study group was located more frequently in the proximal colon than in the distal sites ( $50.0 \%$ vs. $26.2 \%, P<0.05)$. In addition, depressed-type $\mathrm{T} 1$ CRC was more common in the study group than in the control group $(50.0 \%$ vs. $22.5 \%, P<0.05)$. 

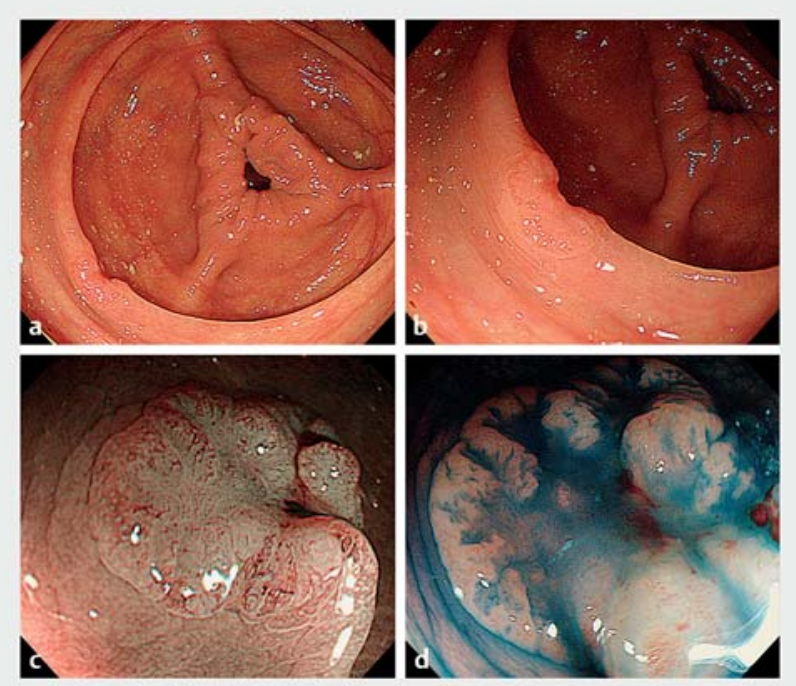

- Fig. 2 A typical case of post-colonoscopy colorectal cancer. An 80-year-old male patient underwent follow-up colonoscopy 716 days after his negative colonoscopy examination, and a $10 \times 9 \mathrm{~mm}$ colorectal cancer (IIa + Ilc type) was identified in the distal ascending colon. The pathological diagnosis was $\mathrm{T} 1$ carcinoma (SM $1250 \mu \mathrm{m}$ ), well-differentiated adenocarcinoma, ly0, v2, pN0. a White-light normal observation. b White-light observation with slight magnification. c Narrow band Imaging observation with magnification. $\mathbf{d}$ Indigo carmine-sprayed observation with magnification.
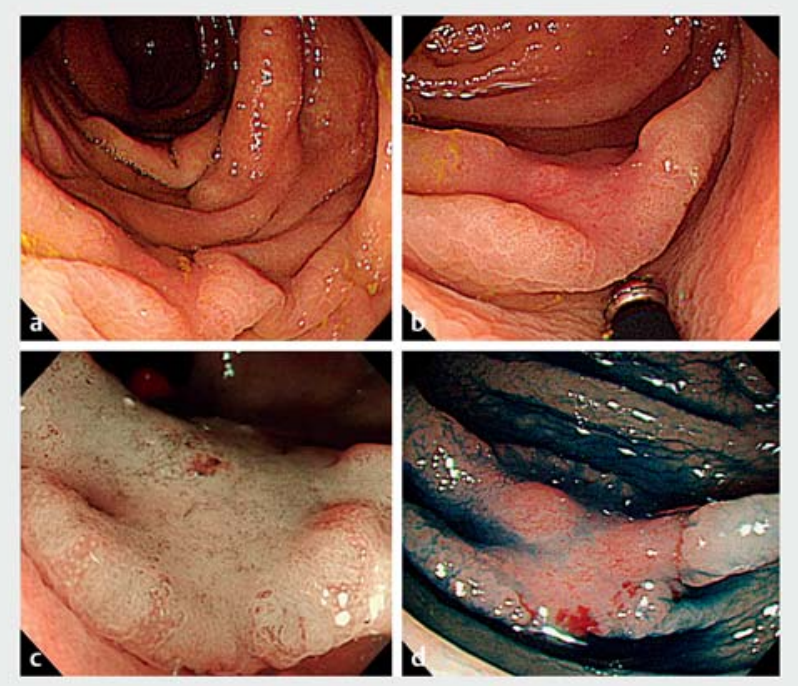

Fig. 3 Another typical case of post-colonoscopy colorectal cancer. An 80-year-old male patient underwent follow-up colonoscopy 840 days after his negative colonoscopy examination, and a $14 \times 9 \mathrm{~mm}$ colorectal cancer (LST-NG pseudo-depressed type) was found in the proximal ascending colon. The pathological diagnosis was T1 carcinoma (SM $1450 \mu \mathrm{m}$ ), well-differentiated adenocarcinoma, ly0, v0, pN0. a White-light normal observation. b Whitelight observation with moderate magnification. c Narrow band Imaging observation with magnification. $\mathbf{d}$ Indigo carminesprayed observation with magnification.
- Table 2 Patient and tumor characteristics in the study and control groups.

\begin{tabular}{|c|c|c|c|}
\hline & $\begin{array}{l}\text { Study group } \\
(n=53)\end{array}$ & $\begin{array}{l}\text { Control group } \\
(n=1989)\end{array}$ & $P$ value \\
\hline Age (y) & $68.9 \pm 11.3$ & $65.6 \pm 11.8$ & $<0.05$ \\
\hline \multicolumn{3}{|l|}{ Sex } & \multirow[t]{3}{*}{0.22} \\
\hline - Male & $35(66.0 \%)$ & $1,125(56.6 \%)$ & \\
\hline - Female & $18(34.0 \%)$ & $864(43.4 \%)$ & \\
\hline Tumor size (mm) & $26.3 \pm 20.2$ & $40.7 \pm 24.1$ & $<0.05$ \\
\hline \multicolumn{3}{|l|}{ Tumor location } & \multirow[t]{7}{*}{0.0636} \\
\hline - C & $3(5.7 \%)$ & $106(5.3 \%)$ & \\
\hline - $A$ & $12(22.6 \%)$ & $286(14.4 \%)$ & \\
\hline - $T$ & $7(13.2 \%)$ & 181 (9.1\%) & \\
\hline - D & $4(7.5 \%)$ & $95(4.8 \%)$ & \\
\hline . $S$ & $13(24.5 \%)$ & 585 (29.4\%) & \\
\hline - $R$ & $14(26.4 \%)$ & $736(37.0 \%)$ & \\
\hline \multicolumn{3}{|l|}{ Tumor stage (T) } & \multirow[t]{5}{*}{0.0587} \\
\hline - $\mathrm{T} 1$ & $22(41.5 \%)$ & $569(28.6 \%)$ & \\
\hline - $\mathrm{T} 2$ & $8(15.1 \%)$ & $298(15.0 \%)$ & \\
\hline - T3 & $18(34.0 \%)$ & 907 (45.6\%) & \\
\hline - T4 & $5(9.4 \%)$ & $215(10.8 \%)$ & \\
\hline
\end{tabular}

C, cecum; A, ascending colon; T, transverse colon; D, descending colon; $S$, sigmoid colon; $R$, rectum.

\section{Discussion}

We sometimes encounter cases of CRC that are discovered during the time interval between the initial negative colonoscopy and the recommended follow-up examination. Such CRCs are termed as PCCRCs [17]. Although some studies discussed the appropriate interval for screening of CRCs after the initial negative examinations $[4,18]$, and several researchers have defined PCCRCs as lesions discovered 6 to 36 months after the initial negative colonoscopy $[19,20]$, the consensus statements by Rutter et.al. [5] are widely accepted. Accordingly, we regarded PCCRC as "interval type PCCRC" which was identified before the next recommended screening or surveillance examination. Moreover, while the prevalence and risk factors of PCCRC have been described in previous studies $[21,22]$, no definitive consensus has been consolidated. In addition, the occurrence of PCCRC is strongly related to the sensitivity and quality of colonoscopy [23,24], while most of the previous reports were based on registry-based data implying that the endoscopic quality was not consistent or guaranteed. In this study, we have clarified the clinical and endoscopic characteristics of PCCRC at our high-volume center, through which a retrospective survey could be precisely performed. As a result, strong relationships between PCCRC and tumor size/location were re- 
- Table 3 Multivariable ORs and $95 \% \mathrm{Cls}$ of patient and tumor characteristics in the study group compared with the control group.

\begin{tabular}{|c|c|c|c|c|}
\hline \multirow[t]{2}{*}{ Characteristics } & \multicolumn{2}{|c|}{ Univariate analysis } & \multicolumn{2}{|c|}{ Multivariate analysis } \\
\hline & OR $(95 \% \mathrm{Cl})$ & $P$ value & OR (95\% Cl) & $P$ value \\
\hline \multicolumn{2}{|l|}{ Age } & \multirow[t]{3}{*}{ N.S } & & \multirow[t]{3}{*}{ N.S. } \\
\hline - $\geq 60$ & $2.1(1.0-4.2)$ & & $1.6(0.8-3.4)$ & \\
\hline - $<60$ & 1.0 (ref) & & 1.0 (ref) & \\
\hline \multicolumn{2}{|l|}{ Sex } & \multirow[t]{3}{*}{ N.S. } & & \multirow[t]{3}{*}{ N.S. } \\
\hline - Male & $1.5(0.8-2.6)$ & & $1.4(0.8-3.4)$ & \\
\hline - Female & 1.0 (ref) & & 1.0 (ref) & \\
\hline \multicolumn{2}{|l|}{ Tumor size } & \multirow[t]{3}{*}{0.0036} & & \multirow[t]{3}{*}{0.0027} \\
\hline - $<30$ & $2.3(1.3-4.0)$ & & $2.8(1.4-5.3)$ & \\
\hline - $\geq 30$ & 1.0 (ref) & & 1.0 (ref) & \\
\hline \multicolumn{2}{|l|}{ Tumor location } & \multirow[t]{3}{*}{0.0189} & & \multirow[t]{3}{*}{0.0154} \\
\hline - Cor A or T & $1.7(0.9-2.9)$ & & $2.0(1.2-3.5)$ & \\
\hline - Dor Sor R & 1.0 (ref) & & 1.0 (ref) & \\
\hline \multicolumn{2}{|l|}{ Tumor stage } & \multirow[t]{3}{*}{ N.S. } & & \multirow[t]{3}{*}{ N.S. } \\
\hline - $\mathrm{T} 1$ & $1.7(1.0-3.0)$ & & $0.9(0.5-1.7)$ & \\
\hline - $\mathrm{T} 2$ or $\mathrm{T} 3$ or $\mathrm{T} 4$ & 1.0 (ref) & & 1.0 (ref) & \\
\hline
\end{tabular}

- Table 4 Distributional and morphological features of T1 CRC in the study group compared with the control group.

\begin{tabular}{|c|c|c|c|}
\hline & Study group & Control group & P value \\
\hline Tumor location & & & $<0.05$ \\
\hline - C, A, T & $11(50.0 \%)$ & $149(26.2 \%)$ & \\
\hline - D, S, R & $11(50.0 \%)$ & $420(73.8 \%)$ & \\
\hline Tumor morphology & & & $<0.05$ \\
\hline - Depressed type & $11(50.0 \%)$ & $128(22.5 \%)$ & \\
\hline - Protruded/flat type & $11(50.0 \%)$ & $441(77.5 \%)$ & \\
\hline
\end{tabular}

C, cecum; A, ascending colon; T, transverse colon; D, descending colon; $S$, sigmoid colon; $R$, rectum

cognized. In addition, right-sided and depressed-type T1 CRC lesions were more frequently found in the PCCRC group.

Proximal sites could be an independent predictor of PCCRC (OR 2.0, 95\% Cl 1.2-3.5, $P=0.0154$ ), consistent with previous studies $[19,25,26]$. Three reasons were indicated. First, the biological features of tumors in the right-sided colon might differ from those in the left side. That is, the serrated pathway for carcinogenesis of CRC or microsatellite instability (MSI)/CPG island methylator phenotypes (CIMP) might be associated with this feature. Regarding the serrated pathway, it is well known that sessile serrated lesions with sessile configuration and in- conspicuous borders are often found in the right-sided colon $[27,28]$. These have as high as or higher malignant potential than conventional adenomas [29]. However, we would like to emphasize that depressed-type T1 CRC was more often found than the other types. Therefore, treating small, right-sided, not only sessile but also depressed-type lesions is necessary to reduce PCCRC occurrence. Arain et al. showed that interval cancers that are more likely to arise in the right-sided colon had a higher MSI and CIMP signature than non-interval cancers [30]. Second, proximal colorectal tumors with advanced histology were frequently small, or had a non-polypoid appearance [31]. Third, anatomical features might be related to overlooking a tumor, because tumors in the hepatic flexure are sometimes difficult to observe. In fact, PCCRC is more common in the hepatic flexure [26].

In addition, our study found that tumor size $(<30 \mathrm{~mm})$ was a significant predictor of PCCRC. Previous studies also showed that tumor size was an independent risk factor for PCCRC [32, 33]. The incidence of PCCRC has been reported to be based on the following three factors: (1) an overlooked tumor; (2) incomplete resection; or (3) specific biological characteristics. Given that several studies have demonstrated that most PCCRC cases were associated with the first two factors (1 or 2), and that the quality of colonoscopy was of the utmost importance [34], we should pay more attention to small-sized lesions in clinical settings.

We also evaluated the macroscopic appearance of T1 PCCRC and revealed that depressed-type T1 CRC was more common than the other types. The information of macroscopic appearance has been scarcely reported because most studies concerning PCCRC relied on registry-based administrative data. However, consistent with our findings, le Clercq et al. also stated that a flat appearance was an independent risk factor for PCCRC (OR $1.70,95 \% \mathrm{Cl} 1.18-2.43$ ) [20]. This might be because, like small-sized tumors, non-polypoid (flat or depressed) tumors could be more easily overlooked in routine practice [35], could be more difficult to resect [36], and could have more progressive potential [37] than polypoid tumors. Although overlooked tumors or incomplete resection were two major causes of PCCRC, as mentioned above, specific biological characteristics including de novo pathway $[14,15]$ could also be important to prevent cancer death from PCCRC. Our results suggested that depressed-type T1 CRC might be a feature of PCCRC ( $>$ Fig. 2 and $>$ Fig.3), and hence more frequent colonoscopies would be required, rethinking current surveillance recommendations or guidelines in the future.

There are several limitations in this study. First, this present study was a single-center retrospective cohort study, and hence all limitations of retrospective studies apply. It was difficult to collect the perfect history or indication of colonoscopy data for all patients, especially those in the control group. However, the large sample size and unified evaluation methods could provide significant reliability. In the case of multicenter studies, it would often be difficult to align the quality of the examinations. Second, although most patients in this study underwent colonoscopy regularly, the evaluation of CRC occurrence relied on patients' self-intent. If patients did not undergo colonosco- 
py, we were not able to perform a colonoscopy on them. Third, in this retrospective study, patients undergoing colonoscopy 1 to 10 years previously at another facility could be classified into the control group, which means that some patients with CRC in the control group might have a history of colonoscopy at another facility. Fourth, not all patients complied with our follow-up schedule after their initial negative colonoscopy. Finally, this retrospective study mainly focused on the clinical and endoscopic characteristics of PCCRCs and their comparison with non-PCCRCs, and many of the patient who received colonoscopy at our hospital were referral cases from other hospitals with wide variety of indications but some with unclear initial colonoscopy date, which makes calculation of incidence of PCCRCs in terms of event (s) per 1000 person-years not feasible and it may not be possible to classify the PCCRCs into any single category as per defined by WEO expert consensus [38]. Nevertheless, in this study, we still provided valuable clinical characteristic of PCCRC.

\section{Conclusions}

In conclusion, our study revealed that PCCRCs are more likely to be smaller in size $(<30 \mathrm{~mm})$ and at a proximal site. Therefore, we must pay attention to small tumors in the right-sided colon to avoid the occurrence of PCCRC. Our large, single-center, cohort study validates previous national cohort studies and provides useful information for endoscopists. In addition, this is the first report to reveal that identifying right-sided, depressed-type T1 CRC is of great importance to reduce PCCRC occurrence.

\section{Acknowledgements}

The authors express great appreciation to Naomi Takenaka for concepting the illustrations and to all members of the Digestive Disease Center and the Department of Pathology, Showa University Northern Yokohama Hospital for their excellent assistance. They also thank H. Nikki March, PhD, from Edanz Group (https://en-author-services.edanzgroup.com/) for editing a draft of this manuscript.

\section{Competing interests}

The authors declare that they have no conflict of interest.

\section{References}

[1] Katanoda K, Hori M, Matsuda T et al. An updated report on the trends in cancer incidence and mortality in Japan, 1958-2013. Jpn J Clin Oncol 2015; 45: 390-401

[2] Fearon ER, Vogelstein B. A genetic model for colorectal tumorigenesis. Cell 1990; 61: 759-767

[3] Winawer S, Fletcher R, Rex D et al. Colorectal cancer screening and surveillance: clinical guidelines and rationale-Update based on new evidence. Gastroenterology 2003; 124: 544-560
[4] Zauber AG, Winawer SJ, O'Brien MJ et al. Colonoscopic polypectomy and long-term prevention of colorectal-cancer deaths. N Engl J Med 2012; 366: 687-696

[5] Rutter MD, Beintaris I, Valori R et al. World Endoscopy Organization Consensus Statements on Post-Colonoscopy and Post-Imaging Colorectal Cancer. Gastroenterology 2018; 155: 909-925.e903

[6] Samadder NJ, Curtin K, Tuohy TM et al. Characteristics of missed or interval colorectal cancer and patient survival: a population-based study. Gastroenterology 2014; 146: 950-960

[7] Robertson DJ, Lieberman DA, Winawer S] et al. Colorectal cancers soon after colonoscopy: a pooled multicohort analysis. Gut 2014; 63: 949-956

[8] Baxter NN, Sutradhar R, Forbes SS et al. Analysis of administrative data finds endoscopist quality measures associated with postcolonoscopy colorectal cancer. Gastroenterology 2011; 140: 65-72

[9] Lakoff J, Paszat LF, Saskin R et al. Risk of developing proximal versus distal colorectal cancer after a negative colonoscopy: a populationbased study. Clin Gastroenterol Hepatol 2008; 6: 1117-1121 quiz 1064

[10] Singh H, Nugent Z, Mahmud SM et al. Predictors of colorectal cancer after negative colonoscopy: a population-based study. Am J Gastroenterol 2010; 105: 663-673 quiz 674

[11] Rex DK, Johnson DA, Anderson JC et al. American College of Gastroenterology guidelines for colorectal cancer screening 2009 [corrected]. Am J Gastroenterol 2009; 104: 739-750

[12] Miyachi H, Kudo SE, Ichimasa K et al. Management of T1 colorectal cancers after endoscopic treatment based on the risk stratification of lymph node metastasis. J Gastroenterol Hepatol 2016; 31: 11261132

[13] Kudo S, Lambert R, Allen JI et al. Nonpolypoid neoplastic lesions of the colorectal mucosa. Gastrointest Endosc 2008; 68: S3-47

[14] Kudo S, Tamura S, Hirota $S$ et al. The problem of de novo colorectal carcinoma. European journal of cancer 1995; 31A: 1118-1120

[15] Kudo SE, Sugihara Y, Kida H et al. Depressed-Type Colonic Lesions and "De Novo" Cancer in Familial Adenomatous Polyposis: A Colonoscopist's Viewpoint. ISRN gastroenterology 2013; 2013: 838134

[16] Kudo S, Tamura S, Nakajima T et al. Diagnosis of colorectal tumorous lesions by magnifying endoscopy. Gastrointest Endosc 1996; 44: 8-14

[17] Sanduleanu S, le Clercq CM, Dekker E et al. Definition and taxonomy of interval colorectal cancers: a proposal for standardising nomenclature. Gut 2015; 64: 1257-1267

[18] Imperiale TF, Glowinski EA, Lin-Cooper C et al. Five-year risk of colorectal neoplasia after negative screening colonoscopy. N Engl J Med 2008; 359: 1218-1224

[19] Cooper GS, Xu F, Barnholtz Sloan JS et al. Prevalence and predictors of interval colorectal cancers in medicare beneficiaries. Cancer 2012; 118: $3044-3052$

[20] le Clercq CM, Bouwens MW, Rondagh EJ et al. Postcolonoscopy colorectal cancers are preventable: a population-based study. Gut 2014; 63: 957-963

[21] Singh S, Singh PP, Murad MH et al. Prevalence, risk factors, and outcomes of interval colorectal cancers: a systematic review and metaanalysis. Am J Gastroenterol 2014; 109: 1375-1389

[22] Kaminski MF, Regula J, Kraszewska E et al. Quality indicators for colonoscopy and the risk of interval cancer. N Engl J Med 2010; 362: 1795-1803

[23] Dekker E, Sanduleanu S. Colorectal cancer: Strategies to minimize interval CRC in screening programmes. Nat Rev Gastroenterol Hepatol 2016; 13: 10-12

[24] Moss S, Ancelle-Park R, Brenner H. European guidelines for quality assurance in colorectal cancer screening and diagnosis. First Edition- 
Evaluation and interpretation of screening outcomes. Endoscopy 2012; 44: (Suppl. 03): Se49-64

[25] Brenner H, Chang-Claude J, Seiler CM et al. Interval cancers after negative colonoscopy: population-based case-control study. Gut 2012; 61: 1576-1582

[26] Richter JM, Campbell EJ, Chung DC. Interval colorectal cancer after colonoscopy. Clin Colorectal Cancer 2015; 14: 46-51

[27] Hasegawa S, Mitsuyama K, Kawano H et al. Endoscopic discrimination of sessile serrated adenomas from other serrated lesions. Oncol Lett 2011; 2: 785-789

[28] Kashida H, Ikehara N, Hamatani S et al. Endoscopic characteristics of colorectal serrated lesions. Hepatogastroenterology 2011; 58: 11631167

[29] Snover DC. Update on the serrated pathway to colorectal carcinoma. Hum Pathol 2011; 42: 1-10

[30] Arain MA, Sawhney M, Sheikh S et al. CIMP status of interval colon cancers: another piece to the puzzle. Am J Gastroenterol 2010; 105: 1189-1195

[31] Rondagh EJ, Bouwens MW, Riedl RG et al. Endoscopic appearance of proximal colorectal neoplasms and potential implications for colo- noscopy in cancer prevention. Gastrointest Endosc 2012; 75: 12181225

[32] Farrar WD, Sawhney MS, Nelson DB et al. Colorectal cancers found after a complete colonoscopy. Clin Gastroenterol Hepatol 2006; 4: 1259-1264

[33] Haug U, Regula J. Interval cancer: nightmare of colonoscopists. Gut 2014; 63: 865-866

[34] le Clercq CM, Winkens B, Bakker CM et al. Metachronous colorectal cancers result from missed lesions and non-compliance with surveillance. Gastrointest Endosc 2015; 82: 325-333.e322

[35] Church JM, Muto T, Appau K. Flat lesions of the colorectal mucosa: differences in recognition between Japanese and American endoscopists. Diseases of the colon and rectum 2004; 47: 1462-1466

[36] Soetikno RM, Kaltenbach T, Rouse RV et al. Prevalence of nonpolypoid (flat and depressed) colorectal neoplasms in asymptomatic and symptomatic adults. Jama 2008; 299: 1027-1035

[37] Voorham QJ, Carvalho B, Spiertz AJ et al. Chromosome $5 q$ loss in colorectal flat adenomas. Clin Cancer Res 2012; 18: 4560-4569

[38] Rutter MD, Beintaris I, Valori R et al. World Endoscopy Organization Consensus Statements on Post-Colonoscopy and Post-Imaging Colorectal Cancer. Gastroenterology 2018; 155: 909-925 
- Supplementary Table 1 Comparison of patient and tumor characteristics between the 12- to 36-month subgroup and the 36- to 120-month subgroup within the study group.

\begin{tabular}{|c|c|c|c|}
\hline & 12- to 36 -month group $(n=47)$ & 36- to 120 -month group $(n=6)$ & $P$ value \\
\hline Age (y) & $69.0 \pm 11.5$ & $68.5 \pm 10.5$ & N.S \\
\hline Sex (male/female) & $32 / 15$ & $3 / 3$ & N.S \\
\hline Tumor size (mm) & $23.8 \pm 15.7$ & $45.7 \pm 38.1$ & $<0.05$ \\
\hline Tumor location (C,A,T/D,S,R) & $19 / 28$ & $3 / 3$ & N.S \\
\hline Tumor stage (T1/others) & $20 / 27$ & $2 / 4$ & N.S \\
\hline
\end{tabular}

